\title{
EVALUATING THE E-SERVICE QUALITY OF MICROBLOGGING
}

\author{
$\mathrm{Hu}$, Yi-Chung \\ Chung Yuan Christian University \\ Chung Li, Taiwan \\ E-mail: ychu@cycu.edu.tw \\ Wang, Jen-Hung ${ }^{*}$ \\ Chung Yuan Christian University \\ Chung Li, Taiwan \\ E-mail: doraemonponpon@ hotmail.com \\ Hung, Li-Ping \\ Chung Yuan Christian University \\ Chung Li, Taiwan \\ E-mail: funforwow@gmail.com
}

\begin{abstract}
More and more famous internet enterprises, such as Google, Yahoo, and Microsoft, participate in the website management of microblogging continuously. However, even though they own high awareness, they are uncertain to take their places in the emerging industry - MICROBLOGGING. Therefore, the microblogging proprietors should think over how to improve their service quality of website to enhance the rate of re-visiting of the users. The past researches about service quality are chiefly by the PZB model, but our study discusses e-service quality which is different from physical service quality, so we take the framework of Parasuraman et al. (2005) as our basic, and interview the experts to build the fitter framework of e-service quality. We think that our study not only has the academic value, but possesses the practical applied value. In addition, we consider that between/ among aspects or criteria exist dependence more or less, so we take ANP (Analytic Network Process) as our major analytic tool to discuss and analyze the key aspects and the key criteria. The results reveal that the key aspects are "Security/ Privacy", "Empathy", and "Efficiency"; the key criteria are "It does not share my personal information with other sites.", "It protects information about my Web-shopping behavior.", "This site is always available for business.", "This site makes it easy to find what I need.", and "Promoting consumers' excitement".
\end{abstract}

Keywords: Microblogging, Service Quality, Analytic Network Process (ANP)

\footnotetext{
* Corresponding author
} 


\section{Introduction}

There are many global famous websites continuously build their own microblogging websites or similar social contact service systems, and try to integrate the internet resource they own to strengthen their strength, such as Yahoo Meme, Digu, Google Buzz, Microsoft Vine, Pixnet Murmur, and so on. From this phenomenon, we can know that the microblogging websites or similar social contact service systems play the decisive role recently.

According to the investigation of Google Zeitgeist (2009), the billboard of keyword searching reveals that Facebook is the second place, Tuenti is the third place and Twitter is the fourth place, which are all social group service microblogging websites. For the result, we can know that the microblogging is presently important development trend of internet application. Take Facebook for example, the inaugurator Mark Zuckerberg announces that in 2009/ 12, the users in global are over 3.5 hundred million, but in 2010/ 07, over 5 hundred million (Eldon, 2010), in addition, in Taiwan, also over 6 million (checkfacebook, 2010).

The microblogging websites develop fast and sharply, so the proprietors should place importance on how to continually keep their competitive strength in the most competitive environment that is their most important topic. A lot of remarkable internet enterprises have upgraded the top 100 global high-tech businesses, such as Amazon.com, Google.com, and Priceline.com, which not only gain the most profits, but own the highest brand awareness, most of all, these enterprises pay the most attention to the service the website offered. According to the result, we can know that excellent service is the most important source of the business profits and the competitive strength. Hsieh and Huang (2005) think the service quality of websites influence the loyalty and the rate of re-visiting of website, in addition, Liu and Arnett (2000) think enhancing the rate of visiting and the rate of re-visiting are the key factors of operation successfully for the websites, and we think they are the sharp weapons that proprietors can continually keep their strength.

According to the investigation of InsightXplorer (2009), it reveals that there are 92\% Plurk users have ever visited Facebook that means the users of the two websites highly overlap. In other words, for the social group website proprietors, they should enhance the service of microblogging to increase the rate of visiting and re-visiting of the users. In the past, the empirical researches about service quality of microblogging are few, so our study thinks that constructing the framework which can appropriately evaluate the service quality of microblogging has the importance and the essentiality. Most of all, it is our major motive. Moreover, our study considers that between/ among aspects or criteria exist dependence more or less, so we take ANP (Analytic Network Process) as our analytic tool to discuss and analyze the key aspects and the key criteria.

As above, the main purposes of our study are (1) Construct the framework of evaluating the service quality of microblogging by the related researches about service quality and interviewing the experts; (2) Find out the key aspects and the key criteria that the users pay the most importance on by ANP; (3) Advance the suggestions by the result analysis to offer the present or future microblogging website proprietors as the reference for improving the e-service quality. 


\section{Literature Review}

\subsection{E-Service Quality}

Due to the operational models are different from the website and the physical shop that makes the definitions of service quality and e-service quality are distinct. Santos (2003) thinks the e-service quality is the whole evaluation of the degree of excellence and quality for the on-line service the website offered. On the other hand, Parasuraman et al. (2005) thinks the website can encourage the browsing, buying, and delivering of goods fast and effective, and Sousa and Voss (2006) think taking the automation ways offers the service for the customers by the virtual interface. As above, our definition is the consumers' entirety evaluation and estimation of on-line service of microblogging. For the aspects of e-service quality, Zeithaml et al. (2000) take means-end to advance the conceptual framework of e-service quality, and reduce eleven aspects that may affect the consumers to measure the e-service quality and which include reliability, responsiveness, assess, flexibility, ease of navigation, efficiency, assurance/ trust, security/ privacy, price knowledge, site aesthetics, and customization/ personalization. At the same time, in 2002, they revise the aspects of e-service quality and the conceptual framework in 2000. They confirm that there are seven aspects that influence the e-service quality, including efficiency, reliability, fulfillment, privacy, responsiveness, compensation, and contact. Parasuraman et al. (2005) take 121 items as evaluating the preliminary scale of e-service quality, and use the extraction and the oblimin of factor analysis to develop the items that can measure the e-service quality, including e-core service quality scale (E-S-QUAL) and e-recovery service quality scale (E-RecS-QUAL). The aspects of two scales are approximately the same as Zeithaml et al. (2002). Parasuraman et al. (2005) just change the aspect from "reliability" to "system availability", but their definitions are identical. In addition, efficiency, system availability, fulfillment, and privacy are formed the e-SERVQUAL (E-S-QUAL) scale which is mainly evaluated the on-line functions the website offered; responsiveness, compensation and contact are formed the recovery e-SERVQUAL (E-RecS-QUAL) scale which is chiefly about the service that consumers hope to get when they have the doubts or troubles.

\section{Establish the framework}

\subsection{Scope and Object}

Our scopes mainly focus on eleven Microblogging websites that include Digu, Plurk, Twitter, Facebook, Meme, Google Buzz, Murmur, MySpace, Buboo, Sina Microblogging, and Yahoo Pulse. On the other hand, our objects are mainly the users in Taiwan who have used or visited one of the Microblogging websites as above, thus, he/ she can answer our questionnaire.

\subsection{Embryonic Framework}

We take seven aspects and thirty-three criteria that Parasuraman et al. (2005) advanced as our basic to evaluate the e-service quality. Recently, microbloggings are all the social contact websites, transaction is not their main core, so we delete the criteria about it. Besides, we integrate the aspects and the criteria of other researches about website service quality to develop the embryonic framework. 


\subsection{Final Framework}

To let the embryonic framework can be fitter our study, we invite five microblogging experts in different domains (A manager in the department of website social contact development, B owner of the consultant firm, $\mathrm{C}$ internet marketing director of the famous business, $\mathrm{D}$ famous blogger and microblogging writer, $\mathrm{E}$ doctoral candidate of the famous university) to do the two phases questionnaire investigation by Delphi technique. In first phase, the experts advance their suggestions and scores for the embryonic framework; in second phase, they answer the influenced degree between criteria. After twice scoring, the criteria in the embryonic framework are all $<0.2$ that means the experts have reached the agreement.

Our study considers that more criteria will lead to more answering time, and lets the answerers do not want to answer, so decreasing the criteria appropriately can enhance the questionnaire accuracy. In view of the above, we sort the criteria that have reached the degree of common consensus, take 60 as our benchmark, and delete the criteria are $<60$. Finally, confirming our final framework.

\section{Methodology}

Saaty advanced ANP (Analytic Network Process) in 1996 that is a multi-criteria method (Saaty, 1996). AHP (Analytic Hierarchy Process) is a one-way hierarchical relational structure, but ANP allows between the decision levels and attributes to exist the more complex relationships. ANP takes network to replace hierarchical feedback, and is the decision analysis which is used in the high and low hierarchy or the directional relationship is not obvious (Meade \& Sarkis, 1999). In ANP, when nodes correspond to levels or components, it means there exists the network feedback in a system (Saaty, 1980). The elements in the nodes may influence some or all elements in other nodes. In the network, all the nodes can be source nodes, intermediate nodes or sink nodes. The relationship in network is represented by the arc and the direction of arrow means dependence relationship (Saaty, 1996). When the two nodes have the external dependence, it will be represented by the two-way arrow; the nodes in the elements have the internal dependence, it will be represented by the circle arc (Sarkis, 2003).

\section{Conclusion}

First, the sorting of aspects is (1) Security/ Privacy (0.237), (2) Empathy (0.155), (3) Efficiency (0.146), (4) Tangible (0.138), (5) System Availability (0.125), (6) Entertainment (0.100), (7) Convenience (0.098), and (8) Responsiveness (0.000). Second, the sorting of criteria is (1) It protects information about my Web-shopping behavior (0.140), (2) It does not share my personal information with other sites (0.140), (3) This site is always available for business (0.093), (4) This site makes it easy to find what I need (0.086), (5) Promoting consumers' excitement (0.077), (6) Visual appealing (0.052), (7) Fun of using the Web site (0.050), (8) Fresh contents (0.046), (9) This site launches and runs right away (0.042), (10) Understanding customers' specific needs (0.041), (11) This site does not crash (0.040), (12) This site enables me to get on to it quickly (0.039), (13) Neat and 
clear items (0.038), (14) It loads its pages fast (0.037), (15) It makes it easy to get anywhere on the site (0.034), (16) The Web site is creative (0.022), and (17) I feel sociable when I use the Web site (0.020). Third, in 2010, Facebook had occurred one event that is the users do not want to use the website anymore. Because Facebook does not consider the users' privacy rights, so they cause a lot of disputes. In our study, the most important aspect is "Security/ Privacy" and the most important criteria are "It protects information about my Web-shopping behavior" and "It does not share my personal information with other sites", so our result responds to the phenomenon of Facebook. As above, we can know that for the users, the website how to protect their personal information and let it be safe is the most important. At the same time, for the business operation, constructing a website that can be trusted by the users is the one and only way. Fourth, when the amount of people increases sharply, such as in 2010/ 07, the Facebook users have been over 5 hundred million in global (Eldon, 2010), it will let the system crash easily and cause the users' complaints. As a result, microblogging website proprietors should enhance the system stability to increase the users' re-using willingness. In our study, the criterion, This site is always available for business, sorts the third that means it is one of the most important criteria, and the result responds to the phenomenon. In the future, if there are more and more users do the social activities by microblogging, the system stability will be the most important thing. Fifth, we take two major parts to explain why the users pay much attention to the criterion, This site makes it easy to find what I need, which sorts the fourth: (1) searching friends: For the most microblogging websites, the performance of this function is recently acceptable; (2) searching the short essay: No matter the vertical axis or the horizontal axis, when the users publish the short essay on the microblogging website, its sorting is by the inverse time (from near to long), and no tagging function to let the users use or distinguish, so it is hard to find the short essay the users want. As a result, we think this function should be improved. Sixth, the criterion, Promoting consumers' excitement, sorts the fifth and its aspect sorts the second, which means it is also important. We think if the microblogging website can let the users feel excellent, it will be contributive to increase the amount of people and get the profits to reach the purpose of sustainable operation. For the users, it will enhance them to raise the website re-visiting, using willingness, and loyalty. Finally, although "Responsiveness" sorts the last, we infer that it does not mean the aspect is not important. Because of the website is free to use, so the users know that it is hard for the website to answer the question or solve the problem instantly. Relatively, if the website can answer the question or solve the problem immediately, thus, it must be popular with the more and more users.

\section{References}

Checkfacebook.com. http://www.checkfacebook.com. (Accessed on Jul. 22, 2010)

Eldon, E. (2010). Facebook announces 500 million users, stories and thanks applications. http://www.insidefacebook.com/2010/07/21/facebook-announces-500-million-users-stories-applicatio n/. (Accessed on Jul. 22, 2010) 
Google Zeitgeist. (2009). http://www.google.com/int1/en_us/press/zeitgeist2009/. (Accessed on Dec. 13, 2009)

Hsieh, S.C., \& Huang, Y.F. (2005). A study for the effect of service quality and trust perception to customer's loyalty on on-line auction. Journal of Information Management - Concepts, Systems, and Applications, 7(2), 91-112.

InsightXplorer. (2009). The Status of Using Microblogging, http://news.ixresearch.com/?p=891. (Accessed on Jun. 6, 2010)

Liu, C., \& Arnett, K.P. (2000). Exploring factors associated with web site success in the context of electronic commerce. Information \& Management, 38(2), 23-33.

Meade, L.M., \& Sarkis, J. (1999). Analyzing organizational project alternatives for agile manufacturing processes: An analytical network approach. International Journal of Production Research, 37(2), 241-261.

Parasuraman, A., Zeithaml, V.A., \& Malhotra, A. (2005). E-S-QUAL: A multiple-item scale for assessing electronic service quality. Journal of Service Research, 7(3), 213-233.

Saaty, T.L. (1980). The analytic hierarchy process. New York, NY: McGraw-Hill.

Saaty, T.L. (1996). Decision making with dependence and feedback: The analytic network process. Pittsburgh, PA: RWS Publications.

Santos, J. (2003). E-service quality: A model of virtual service quality dimensions. Managing Service Quality, 13(3), 233-246.

Sarkis, J. (2003). Quantitative models for performance measurement systems - alternate considerations. International Journal of Production Economics, 86(1), 81-90.

Sousa, R., \& Voss, C.A. (2006). Service quality in multi-channel services employing virtual channels. Journal of Service Research, 8(4), 356-371.

Zeithaml, V.A., Parasuraman, A., \& Malhotra, A. (2000). A conceptual framework for understanding e-service quality: Implications for future research and managerial practice. Working paper No.00-115. Marketing Science Institute.

Zeithaml, V.A., Parasuraman, A., \& Malhotra, A. (2002). Service quality delivery through web sites: A critical review of extant knowledge. Journal of the Academy of Marketing Science, 30(4), 362-375.

Zuckerberg, M. (2009). An open letter from Facebook Founder Mark Zuckerberg. http://blog.facebook.com/blog.php?post=190423927130. (Accessed on Dec. 13, 2009) 